\title{
WARRING TAUTOLOGIES: MORAL DISSENT FROM A COGNITIVIST PERSPECTIVE
}

\author{
MATTHIAS KIESSELBACH \\ (Universität Potsdam - Germany)
}

\begin{abstract}
It is commonly thought that the prevalence of moral dissent poses a problem for the moral cognitivist, forcing her to diagnose either a lot of misunderstanding, or a lot of unexplained observational error. Since mere misunderstanding can be ruled out in most cases of moral dissent, and since the diagnosis of widespread unexplained error is interpretively unstable, prevalent dissent has pushed many philosophers towards non-cognitivism. In this essay, I argue that once a diachronic, pragmatist theory of language along the lines of the latest Wittgenstein is employed, a third interpretive option becomes available to the cognitivist. Besides the diagnostic options of misunderstanding and factual disagreement, she can argue that a given case of moral dissent is an instance of grammatical tension. This interpretation not only saves moral cognitivism, it also has some attractive theoretical implications. Among other things, it yields an elegant way of solving the current debate around moral particularism.

Key-words: Moral Cognitivism, Moral Dissent, Inferentialism, Linguistic Evolution, Moral Objectivism, Wittgenstein
\end{abstract}

An earlier version of this paper was presented at the 2008 Winter Academy of the Forum Scientiarum, Tübingen, Germany, and at the 2008 Wittgenstein Symposium in Kirchberg, Austria. I am grateful for many interesting and useful comments from philosophers attending these conferences. Special thanks are due to Andrew Pickin, Niels Weidtmann and Eugen Pissarskoi.

\section{Introduction}

There are many good reasons to treat ordinary moral utterances as factual claims. We argue for them, we employ them as premises, we endorse them as true, we reject them as false, and we use them to pin down elusive conflicts between speakers. Or so, I hasten to say, it seems. Yet many philosophers hesitate to interpret moral utterances as full-blown propositions. Part of what explains their hesitation is the prevalence of moral dissent. It is quite clear, however, that prevalent dissent by itself is hardly a sufficient reason to block a cognitivist reading of moral talk. Dissent, after all, is a familiar feature of virtually all domains of discourse, including science. What lies at the root of their non-cognitivist hesitation must therefore be something a little more complex.

It is the thought that the nature of moral utterances is such that if they were propositions, then moral dissent would confront us with a dilemma. The parties to a conflict over a proposition either disagree, or they merely misunderstand each other. If they genuinely disagree, it is trivially the case that at least one of the conflicting parties has got it wrong. Since an ordinary moral utterance is a reaction to the speaker's circumstances and thus comes out, on a cognitivist reading, as an observation report, we are forced to diagnose observational error. The more cases of moral conflict 
are thus described, the more we are drawn to the unhappy conclusion that in morals, observational error abounds. The only alternative, though, is to say that the conflicting parties misunderstand each other. On this view, they just use their vocabularies in different ways and are therefore, if anything, in need of an interpreter. In the case of moral dissent, however, this view conflicts with the finding that dissenting parties frequently condemn not just each others' words, but also each others' actions. Since moral utterances are logically connected to action, and conflicting parties do things differently, it is unsatisfactory to see the problem as merely one of translation.

In this paper, I shall provide the outlines of a theory of language on which no such dilemma arises for moral cognitivism. While it is true that most moral utterances are reactions to the speaker's circumstances and do have logical connections with action, the prevalence of dissent need not bring a cognitivist interpretation of moral discourse to a halt. If we see language as an evolving system, then a third interpretive option besides factual disagreement and mutual misunderstanding becomes available for moral dissent. More specifically, once we see that the source of linguistic evolution is grammatical tension, we can interpret many instances of moral dissent as conflicts over different ways to resolve such tension. It will be seen that this type of moral dissent can usefully be described as conflict between incompatible tautologies.

In order to explain just what is meant by "incompatible tautologies", how moral dissent can be thus described, and what is gained by such an interpretation, I will take four steps. In the next section, I will introduce a cognitivist conception of moral discourse, featuring the idea that moral utterances are non-inferential, propositionally structured responses to aspects of reality. In this, I will draw on certain attempts to bring Wittgenstein to moral philosophy, most notably on Sabina Lovibond's "metaphysically homogeneous" conception of language (Lovibond 1983: 25). In the third section, I will bring out the problem with this conception of language, which consists in its inability to deal satisfactorily with prevalent moral dissent. In the fourth section, I will complement the cognitivist view of moral discourse with a theory of linguistic evolution, also inspired by the later Wittgenstein. This theory centers on the phenomenon of inconsistencies in the framework of grammatical rules and makes it possible to see many cases of moral dissent as cases of dispute over different ways to resolve such tensions. Since this dispute is over different ways of extending existing grammar beyond its familiar domain, and since grammar shows up in tautologies, it can be described as a dispute over "incompatible tautologies". In the fifth section, I will conclude by defending this view against various counter-arguments and by drawing attention to the appealing side-effect that it provides a way out of the debate between "particularism" and "generalism".

\section{A Cognitivist Conception of Moral Discourse}

Let us start with a cognitivist conception of moral discourse inspired by the later Wittgenstein. Wittgenstein, of course, is not usually thought of as a "cognitivist". This is due in part to his well- 
known reluctance to embrace "philosophical doctrines" (Wittgenstein 2001 [PI]: I: 1281), and in part to his professed impatience with ethical talk. ${ }^{2}$ However, Wittgenstein's later work contains aspects which are warmly applauded by contemporary moral cognitivists.

Firstly, in distancing himself from the picture-theory of meaning and in embracing the idea that all talk of "meaning" is a way of discussing the use to which an expression is put, the later Wittgenstein helps us accept that a moral utterance is semantically as respectable as any expression for which there is an established use. Secondly, with his manifold attempts to decontaminate our descriptions of an expression's use of the illusion that every expression refers to something, Wittgenstein helps us see that the lack of a referent need not be a death-blow to a moral utterance. Moreover, when such an expression does refer, it may very well involve morally laden predicates. Thirdly and crucially, through his rejection of the Fregean idea that behind the grammatical form of some expression, there lies a logical gestalt which the grammar can succeed or fail to capture, Wittgenstein helps us overcome our suspicion that moral utterances routinely mislead us about their real nature. To be sure, grammar can mislead, but only by drawing our attention away from the use of our expressions. Since moral utterances are used as propositions and thus as figuring in inferences and as being true or false, Wittgenstein helps us guard against the view that they are just emotive ejaculations or orders in disguise.

One of the most memorable formulations of a view like this is Sabina Lovibond's Realism and Imagination in Ethics (1984), which I take as a starting point for an elaboration of Wittgensteinian cognitivism. Lovibond reads Wittgenstein as offering us "a homogeneous or 'seamless' conception of language[,] ... a conception free from invidious comparisons between different regions of discourse." (Lovibond 1983 : 25) According to Lovibond, Wittgenstein rejects the idea that an utterance's "stating facts" or "describing reality" is something over and above its taking the grammatical form of a proposition.

\footnotetext{
On this view, the only legitimate role for the idea of 'reality' is that in which it is coordinated with ... the metaphysically neutral idea of 'talking about something'. ... It follows that 'reference to an objective reality' cannot intelligibly be set up as a target which some propositions - or rather, some utterances couched in the indicative mood - may hit, while others fall short. If something has the grammatical form of a proposition, then it is a proposition: philosophical considerations cannot discredit the way in which we classify linguistic entities for other, non-philosophical, purposes... (Lovibond 1983 : 25f.)
}

Since moral utterances “qualify by grammatical standards as propositions" (Lovibond 1983 : 6f.), we are warranted to take them as stating facts, just like we do with everyday propositions about, say, physical objects. In order to back up her bid, Lovibond proceeds to a more specific discussion of moral utterances. Here, her central claim is that moral utterances can be interpreted 
as non-inferential observation reports (Lovibond 1983 : 10ff.). In this context, Lovibond cites Mark Platts approvingly, who writes that "[w]e detect moral aspects [of a situation] in the same way we detect (nearly all) other aspects: by looking and seeing." (Platts 1979 : 247, cited in Lovibond 1983 :11)

The concept of "non-inferential report" is borrowed from Wilfrid Sellars, who uses it to describe statements which are uttered in reaction to sensual stimulation, but which at the same time stand - to put it in Sellarsian jargon - in "the logical space of reasons". ${ }^{3}$ For Sellars, the semantic content of any expression is a matter of its logical connections with other expressions. The proposition is singled out, in his theory, as the expression which serves both as antecedent (or reason) and as consequent (or consequence) in material inferences: knowing what a proposition means is knowing what it follows from and what follows from it. ${ }^{4}$ Since a proposition is inferentially connected with other propositions, it is a holistic phenomenon. The idea behind a "non-inferential report", now, is that propositional utterances also have non-inferential - i.e. practical - conditions and consequences of use. Often, a proposition is uttered in direct, non-inferential, reaction to sensual stimulation. If the speaker making the propositional utterance is taken by her interpreters as a reliable responder to her non-linguistic circumstances, they will take her proposition as an acceptable warrant to adopt the proposition themselves. The utterance in question counts as a "non-inferential report". From the perspective of moral cognitivism, this view is attractive, because it brings two well-established aspects of moral utterances together in a propositional reading. On the one hand, we frequently adopt moral statements in reaction to our circumstances, yet without somehow inferring them; on the other hand, we rely on the fact that moral statements figure in the logical space of reasons.

Part of the philosophical weight of this reading of moral discourse rests on the way our moral utterances are actually constructed. Lovibond is very clear that on this point, she differs from classical (and thus generally non-cognitivist) moral philosophy to some extent, insisting that a paradigmatic moral utterance features concepts which are "governed by impersonal criteria [of use]" (Lovibond 1983 : 14, my emphasis). She concurs with David Wiggins who stresses "evaluative moral propositions typified by 'x is brave', 'malicious', 'corrupt"' of which it would be "either false or senseless to deny that they involve reference to properties in a (real) world" (Lovibond 1983 : 14, referring to Wiggins 1998 : 95). She also agrees with Mark Platts, who, "in a similar vein, regards moral concepts with a concrete, descriptive content as 'the interesting, basic terms' of moral assessment" (Lovibond 1983 : 15, referring to Platts : 246). In effect, then, Lovibond insists that we couch our everyday moral statements in the kinds of terms which Bernard Williams has labeled "thick ethical concepts", i.e. terms which wear their empirical content on their sleeve, as opposed to "thin" concepts like "good", "indefensible" or "ought (to be done)" (Williams 1984 : 129).

It is important, though, that while Lovibond's report on the vocabulary used in standard moral utterances helps us see their propositional nature more clearly, her theory does not strictly depend on it. The theory can be stretched to cover propositions involving thin ethical terms as well. We can 
see this if we allow that two tokens of a thin term like "good" often have very different conditions of application. This licenses us to say that the two tokens actually represent two different properties, in spite of sharing the same phonetic or orthographic form. In some contexts, this is clear: "good" at the hairdresser quite obviously means something else than "good" at the ice cream van. The same can, however, also be true in less obvious cases. The clue is to reverse the order in which thin and thick ethical terms are taken to depend on each other.

While many people think that we first learn what "good" means - namely: endorsement - and then learn what, say, "generous" means - namely: giving away lots of things, plus the information that this kind of behavior is good - this view might get the order wrong. We cannot learn "thin" endorsement terms like "good" (and their opposites, like "bad") until and unless we are familiar with a variety of terms like "generous" ("stingy", "courageous", etc.). On this view, thin endorsement terms represent complex theories of the interaction of thick moral predicates. In other words, what you mean by "good" in a given context depends on your implicit theory of how the pertinent thick ethical terms come together in that context. "Good" thus marks a complex concept (which can differ from context to context or speaker to speaker), but it is no less empirical for that. ${ }^{5}$

On a theory like Lovibond's, then, the fact that moral utterances are reactions to speakers' circumstances is reflected in the affirmation that moral utterances are empirical statements, even if they feature thin concepts. However, there is another aspect of moral utterances which a decent interpretation must take into account: moral utterances stand in logical relations with action. What this means is that if I say: "there is nothing more terrible than $\Phi$-ing", and go on to $\Phi$ in the very next minute, you are perfectly warranted to conclude either that I did not understand what I said, or that I am practically irrational (or, perhaps, that I lied). It is just like the fact that someone who says "If P then Q" and "P", and then goes on to claim that not-Q or to act as though not-Q, either does not understand what he says or is irrational (or is lying).

This aspect of moral utterances has been deemed problematic by some philosophers operating with classical theories of meaning. If you think that the meaning of a proposition is fundamentally a matter of reflecting the physical world, then the idea that a proposition can demand certain courses of action as a matter of its logic will seem absurd. On a Wittgensteinian account of language, however, things are different. Since it conceives all utterances as maneuvers in language games which are always continuous with non-linguistic action, it would rule out as absurd the idea that a proposition has no logical connection with action. In fact, if there is anything to explain for a Wittgensteinian theorist, it is the seeming impracticality of certain scientific propositions. Here, the Sellarsian view is that they, too, are indeed practical: scientific propositions are, after all, employed in material inferences. If this does not seem practical enough, note that inferential chains always give rise, at some point, to non-linguistic action. ${ }^{6}$ Seeing moral utterances as non-inferential, propositionally structured observation reports thus allows us to affirm that they are used as responses to a speaker's circumstances and that they are logically connected with both other propositions and with action. 
So far, however, the theory may not convince every reader, for we have assumed that all indicative moral sentences figure as non-inferential, empirical reports. ${ }^{7}$ On the face of it, however, this is not very plausible. While many moral utterances go through - "This was just cruel”, "Mary's constant lying is cowardly" or "He shows a remarkable capacity for compassion" - there is another type of indicative moral statement whose members do not seem to qualify as non-inferential observation reports. Consider the following remarks: "Cruelty is always wrong", "Sometimes a lie is warranted in the name of love", or (though this one is not all that plausible) "Compassion is just a kind of weakness." Certainly these sentences are moral propositions; however, it is hard to imagine that they ever figure as non-inferential reports of empirical observations.

I want to claim that we encounter, here, a very different type of proposition. Following an idea of Cora Diamond's, I will argue that these remarks function much like mathematical propositions (see Diamond 1996 : esp. 231f.) ${ }^{8}$. Contrary to Diamond, however, I shall claim that they do not force us to give up Lovibond's view of language. Rather, they suggest an elegant way to complete it. In fact, the Wittgenstein-Sellars theory of language, on which we have already rested quite a bit of weight, happily embraces these remarks as propositions with a (predominantly) grammatical use.

I am aware that this suggestion seems hard to swallow at first, but let me remind you of a few more details of Sellars' theory of language, and show just how grammatical propositions fit into the picture. At the theory's center stands the familiar idea that language must ultimately be understood pragmatically. That is, all talk of "meaning" or "content" is a way of discussing the use of expressions. However, in order for us to legitimately speak of language, the different uses of a set of expressions must interlock. Expressions must be connected - via rules - firstly with nonlinguistic phenomena in the circumstances of their utterance as well as with action accompanying it, and secondly with other expressions. (Sellars calls the first set of connections "language entry and exit transitions" and the second set "intra-linguistic moves"; see e.g. Sellars 2007c : 36) For this reason, language is not just a box of diverse tools; it is a practical calculus or, to use a Wittgensteinian term, a kind of game.

One aspect of the game of language which must be kept in mind, and which singles it out from other games such as chess or football, is that its substantive moves and the formulations of its rules are alike in form. Both are articulated as expressions in language. More specifically, the favored kind of expression for both moves and rules is the proposition. My claim, now, is that empirical propositions are substantive moves in the game of language (analogous to the moving of chess pieces), while grammatical propositions can be said to bring out or determine the game's rule-work. In order to see this more clearly, let us take a closer look at the expressions known as propositions.

I have already drawn your attention to the inferential nature of propositions. There is a second aspect to take into account, though: propositions have a sub-sentential structure. The fact that propositions have parts - most conspicuously, singular terms and concepts - is supremely 
important because it makes it possible for us to construct ever new propositions and to rely on their being immediately understood. What anyone operating in a pragmatist theory of language must understand, now, is that these parts are not somehow given to us. We derive them, rather, from our acquaintance with existing material inferences and, hence, with existing propositions. The idea is that inferential relationships between complete sentences depend on substitutional relationships between sentence-parts, and vice versa. ${ }^{9}$ It is for this reason that once we know the substitutional, or logical, behavior of a concept, we can decipher any novel proposition involving it. We are now at the point where we can say just what a grammatical proposition is.

While all propositions exhibit aspects of a concept's logical behavior - if only by connecting it with a singular term -, some propositions do this in order to inform the audience about the world, while others do this in order to determine how a concept is used. With the former kind of proposition, we exploit our audience's familiarity with the logic of the employed concepts in order to make them aware of some fact they did not previously know. With the latter kind of proposition, which may well be tentative or experimental, we exhibit one or more conceptual connections to be taken as norms of expression when interpreting other utterances of ours. We call this kind "grammatical". Going back to our initial examples, we can now see that a statement like "Cruelty is always wrong" can be seen as informing an audience how we use the word "cruelty". It is, of course, far from a complete account, but it does highlight an important logical aspect of it (namely one of its consequences of application). We can also begin to see how one might get the idea of interpreting this kind of remark as on a par with with mathematical propositions: as the remark serves to make a part of the usage rules of the concept of cruelty explicit, a proposition like " $5+7=12$ " serves to make a part of the usage rules of its symbols explicit. Once grammatical facts like these are firmly understood, speakers can go on to make interesting empirical statements, like "Peter acts wrongly" or "There are 12 cows on the meadow". Note that only empirical statements can be true or false in the usual sense. Calling a grammatical proposition "false" indicates only that a different system of expression - a different language - is drawn on. Grammatical propositions, then, are used to calibrate the scales, while empirical propositions serve to weigh the goods. ${ }^{10}$

From this piece of theory, it follows that whether a proposition is grammatical or empirical is not a matter of its construction, but of its use. Wittgenstein - quite far ahead of his time - has clearly seen this point when he remarked that

Sentences are often used on the borderline between logic and the empirical, so that their meaning changes back and forth and they count now as expressions of norms, now as expressions of experience. (For it is ... the use, which distinguishes the logical proposition from the empirical one.) (Wittgenstein 1978 [RC]: I:32) ${ }^{11}$

It is for this reason that we can allow that a moral statement like the remark on cruelty 
actually figures as a piece of grammar. In the coming sections, there will be more to say about this idea. For now, I want to provisionally conclude this sketch of a cognitivist conception of moral language with three observations and a promissory note. Firstly, the adapted theory retains the attractive feature of displaying moral statements as of the same species as scientific statements. The duality of empirical and grammatical propositions can be observed in all propositional areas of discourse. Secondly, the decision to embrace certain moral propositions as grammatical suggests that "objectivism" would be a more fitting name for the theory than "realism". The empirical world, of course, still features prominently in our pragmatist theory, but it is now mediated by grammar. Thirdly, the ideas presented here might go against philosophical habits, but one should not think that they can easily be disproved by a look at actual linguistic practice. No aspect of language use was postulated, we just gave it a new interpretation. And here is the promissory note: embracing certain moral utterances as grammatical is not only a way to save cognitivism, it will also richly repay us in other ways. Before we can see this, however, we must acknowledge the real problem threatening our theory.

\section{Moral Dissent between Disagreement and Misunderstanding}

Initially, we have good reason to welcome the adapted cognitivist conception of language as having a substantial advantage over classical conceptions: it is very well placed to avoid an old problem of cognitivism, namely the strong pull towards describing each and every moral conflict as a genuine disagreement. This pull is a problem because it forces cognitivists to diagnose a lot of observational error, which is, after all, a rather harsh charge. (Remember that in a disagreement, at least one of the disagreeing parties must be wrong!) With the adapted version of cognitivism, things are different. Since it insists that the meaning of a proposition lies, in crucial part, in its inferential relations with other propositions whose meanings, in turn, are also inferentially fixed, it makes it much easier to interpret a given moral conflict as a complex misunderstanding. It makes it easier, that is, to declare that the conflicting parties are just committed to different grammatical norms that they are talking past each other. The clearest examples of moral conflicts which turn out to be misunderstandings involve thin ethical concepts, because with them, it is particularly easy to see how interlocutors can wrongly believe to be disagreeing about the world, when in fact they just talk about different properties.

However, the choice with which the new conception of moral discourse leaves us is not as rich as we need it to be. There will be instances of moral conflict for which neither disagreement nor misunderstanding is a plausible diagnosis. The trouble comes when we acknowledge the sheer number of instances of moral conflict which prove resistant to all attempts to see in them mere misunderstandings. Logically, there remains the option, of course, to insist in every such case that 
at least one of the conflicting parties must be factually wrong and thus in observational error. But at some point, we will have to ask ourselves whether there is not a better philosophical interpretation than one which implies that moral discourse is widely and persistently contaminated with error for which we have no independent explanation. ${ }^{12}$

If there were no way around this problem, then it would bring moral cognitivism to a halt. Even though its theoretical rival is extremely counter-intuitive, we would have to settle for some version of non-cognitivism and fix its problems as well as we can. Before introducing my own solution, I want to discuss Lovibond's rescue attempt, which represents a group of similar ideas in the cognitivist camp.

Lovibond claims that some propositional "language games" (and some of them more so than others) allow for a third option besides disagreement and misunderstanding. Her idea is that objectivity, which she understands as the logical pull towards the judgments of certain intellectual authorities, is unevenly distributed across different language games. Some language games are such that "within [them], it is not essential to secure a high degree of uniformity in the way people respond to a given situation", while others "involve a training process which is not complete until all personal idiosyncrasies have been eliminated" (Lovibond 1983 : 66). An example of the former kind of language-game is discourse about whether something is "fun" or not; an example of the latter kind is discourse about whether or not something "is a table". In the former case, there is variety among different people about what is fun, without this implying that anyone makes a mistake. With "being a table", on the contrary, there are virtually no legitimate differences of use (apart from some inevitable vagueness). Every time we encounter divergences of use, that is, someone steps outside of the language game altogether. Moral discourse, now, is located somewhere between these two extremes in terms of the strength of the pull towards uniformity (Lovibond 1983 : 67f.). There is a stronger pull towards uniformity than in contexts of predicates like "fun", but it is weaker than it is in contexts of predicates like "is a table". We can thus differ in morals without properly disagreeing.

This reaction is certainly built on something we can recognize. However, as a solution to the problem, it fails. It is not that the claim that common linguistic practice tolerates a divergence in the attributions of moral predicates is false. The problem is, rather, that the claim's import is shaky on theoretical grounds. Even if empirical linguistic studies found that ordinary speakers employ moral terms in divergent ways similar in kind (if not in degree) to the case of "fun", it must still be shown that the different speakers fully understand each other while so diverging. This, however, is an interpretive claim. It is for the philosopher to make this interpretation, and she will be guided by how demanding her notion of "understanding" is. Since we have, so far, employed a rather demanding notion of "understanding", we would be very likely to conclude that even in the case of "fun", a seeming mutual understanding might well turn out to be a misunderstanding, once the different speakers have put their views of the term's conditions and consequences of use, i.e. 
the term's logic, on the table. Note that when someone persistently laughs in the wrong times, we say that "we do not understand him". Since I see no principled reason for interpretive tolerance in the face of divergences of this kind, I see no such reason in the interpretation of moral discourse either. All that we can safely take home from the rescue attempt is that we do not have to care about misunderstandings equally much in different areas of discourse. But this is not what is needed to solve the problem. I conclude, thus, that the problem facing cognitivism is still on the table.

\section{A Diachronic View of Language}

The problem, to recapitulate, is that the two interpretive options on offer for propositional conflicts - genuine factual disagreement and mutual misunderstanding - do not suffice for all cases of moral dissent. While we can rule out mere misunderstanding in many cases, the remaining number of moral conflicts is so high that we run into interpretative barriers, if we diagnose observational error in all of them. Of course, it is not logically impossible that a lot of people are badly wrong in a lot of cases (without there being an independent explanation of this fact). But there is a strong pull away from any philosophical theory which implies something like this.

The solution I am going to present holds that there is indeed a third interpretive option for moral dissent, though one that looks different from what Lovibond has proposed. In fact, the third interpretive option remains barred until a significant change of perspective is effected. The theory as so far presented is decidedly synchronic. It treats the game of language as a static system. My claim is that everything that has been said about semantic content so far must be interpreted as describing only a time slice of an essentially evolving system. A complete theory of language must be diachronic. In this section, I will present the outlines of a diachronic theory of language whose point of departure are the very latest writings of Wittgenstein and whose appeal is the fact that it yields a third interpretive option for the phenomenon of moral dissent. Since the theory has much to do with the role of grammatical propositions, let us start by taking a closer look at them.

A grammatical proposition, as we have seen, can be said to inform the audience about how a concept functions, rather than about what the world is like. It is distinguished by its use. But what is the use of talking about words, not the world? It seems that there are at least three such uses. Firstly, in teaching someone new or unfamiliar concepts, we frame simple propositions involving these concepts. Secondly, in heated arguments, we often check that we are not talking past each other by formulating certain salient propositions. Thirdly, in new and unclear cases of observation - about which I will have more to say later -, it is often helpful to go back to clearer propositions. All these grammatical uses of propositions connect well with something we have already seen: it is not a meaningful move to seriously negate a grammatical proposition. Whenever 
someone purports or seems to doubt or deny a proposition meant as a piece of grammar, he must be interpreted as proposing to end the current language game, and to start a new one. Incidentally, this is why grammatical propositions are comparatively rare. They express inferential relationships which are considered non-negotiable. ${ }^{13}$

Now, what is important, and of what the later Wittgenstein is increasingly aware, is that just what is considered non-negotiable is subject to change over time. A logical relation considered non-negotiable today may be up for grabs tomorrow (Wittgenstein 1972 [OC]: 256), and vice-versa (Wittgenstein 1972 [OC]: 210f.). In other words, a proposition which can only figure as grammatical today might be used empirically tomorrow, and vice-versa. Of course, such a thesis could be upheld in the context of a synchronic theory of language. On such a theory, however, the change would be interpreted as exogenous, as a mutation of language. The theory would have nothing to say about why such a language change occurs, and what kind of changes may be expected in the future. For these questions, a diachronic theory is needed. ${ }^{14}$

The good news is that the work of the later Wittgenstein includes one - in fact, an exceedingly simple one. Wittgenstein's diachronic theory holds that different logical background connections - i.e. grammatical rules - can come into conflict with one another once a given language game is confronted with a non-linguistic phenomenon which has not previously been practically relevant. In these situations, we are forced to reject at least one of the conflicting grammatical rules, thereby altering the shape of our language game even in familiar situations. Before spelling out the theory in more detail and locating it in Wittgenstein's writings, let me give a very simple example taken from an innocent period in the history of science.

Let us go back to the time of the Ancient Greeks, and consider the following two remarks (uttered back then): "Something that is gray, swims in the water, never comes ashore and has fins and a tail is a fish" and "Fish lay eggs and have no lungs". It is very plausible that in Ancient Greece, these propositions were only used in teaching barbarians Greek, and maybe also in philosophical symposia or in encounters with exotic beasts such as squids or seals. In other words, these propositions are very likely to have had an exclusively grammatical use. Imagine, now, the day when the first whale was cut open, or seen giving birth. What did people say? Did they say "It is gray, swims in the water, etc., therefore it must be a fish", or did they say "It has lungs etc., therefore it is no fish"? Well, there were probably those who favored the first statement and those who favored the second. Until, that is, someone with insight joined the discussion and said "You're both right in some sense, and wrong in another. We never had to deal with such a creature before, at least not in the way we do now. Since we might encounter another specimen in the future, let us find a new zoological classification scheme that best suits our current and projected future needs."

The end of the story is well-known. Today, the former proposition counts as a false empirical statement, while the latter has retained its status as grammatical and thus cannot, on pain of violating 
logic, be called into doubt. In other words, we no longer operate with the inference from greyness, tail, fins, swimming and not coming ashore to being a fish, while we still operate with the inference from being a fish to laying eggs and having no lungs. ${ }^{15}$ The way we now talk about cetaceans has a good (meta-)reason ${ }^{16}$ going for it: scientific articles in the fields of fishery or marine biology can be shorter at the same level of precision than they could have been on many other solutions. But ask yourself, now, how exactly the dialectical situation before the appearance of the insightful zoologist is to be described. On the one hand, the two groups certainly disagreed in some sense. On the other hand, their disagreement was not strictly speaking factual. There were also elements, then, of the kind of case in which we would diagnose that people talk past each other. Moreover, the dissenting parties knew very well that their opponents had good grounds for what they said. My point, here, is of course that in a diachronic theory of the kind envisioned, we need a third category for propositional conflicts.

Since, in the sketched situation, two grammatical propositions come into conflict, I propose to speak, with a hint of provocation, of "conflicting tautologies". Note that these sentences are "empty" in the sense of being only about how we use bits of language; but that they are anything but "empty" in that they are operative in determining how we act. On a Wittgensteinian theory, language is never disconnected from practice - grammatical propositions are rules of our language game(s). (If the practicality of grammar is not yet clear, it will become clear below.)

Wittgenstein has come to see the phenomenon's centrality clearly - both in terms of its import, and in terms of its frequency. It should thus pay off to take a closer look at the exposition of his theory. The idea of language as an evolving system first finds expression in Wittgenstein's famous "builders' language game" of the Philosophical Investigations ${ }^{17}$, in which the only linguistic tools used by a group of builders consist in one-word-sentences like "Slab!", "Block!", "Pillar!" etc. The builders utter these sentences in order to make their peers bring the respective objects. Wittgenstein's main target in his discussion is the idea that the grammar of natural language is already complete and thus static. This idea surfaces, for example, in our inclination to say that the builders' one-word-sentences are short for "Bring me one slab" and "Bring me one block". Wittgenstein argues that a thesis like this is notoriously misleading: our long sentences only make sense in the context of a variety of very complex practices, which include ordering, stating, asking, referring to various people, and counting. Since the builders' situation is expressly designed as not featuring these practices, we cannot attribute to them mastery of words like "bring", "me" or "one". All these grammatical possibilities develop only together with the relevant practices.

But Wittgenstein is not only committed to the view that our expressive resources evolved from primitive linguistic tools. He is also committed to the idea of ongoing grammatical change. Let me retrace this theme in a few sentences. In the middle period of Wittgenstein's philosophy, the view that natural language is a complex practical calculus, or game, is fully worked out. It is an implication of such a semantic theory that all communication partners must converge on a great deal 
of rules in order to be able to interpret each other as playing the same game. Since the distinction between grammatical and empirical propositions is a matter of use, and since all propositions convey some grammatical information, what must be shared are propositions tout court:

If language is to be a means of communication there must be agreement not only in definitions but also (queer as this may sound) in judgments. This seems to abolish logic, but does not do so. - It is one thing to describe methods of measurement, and another to obtain and state results of measurement. But what we call "measuring" is partly determined by a certain constancy in results of measurement. (Wittgenstein 2001 [PI]: I: 242)

We have already witnessed this phenomenon in passing: someone who persistently calls unfunny things funny must mean something different by "funny" than we do. Wittgenstein's own examples are drawn from the talk of measuring (as seen here and e.g. in Wittgenstein 1983 [RFM]: I:5, I:148ff) and calculating (Wittgenstein 1983 [RFM]: IV: 24, V:26), talk of colors (Wittgenstein 1978 [RC]: I:66, III:86ff., III:30ff., III:42, III:123f., III:127) and of mental and intellectual acts (Wittgenstein 1983 [RFM]: I:116, I:131, I:135). To give just one example: someone who persistently differs from our color judgments - and who is not visually impaired or a liar - must either be interpreted as using different words for our familiar colors, or as not talking about colors at all. People who see colors that are different from ours altogether - but which are still colors - are logically impossible. "There is, after all, no commonly accepted criterion for what is a color, unless it is one of our colors" (Wittgenstein 1978 [RC]: III:42) At the same time, it is undeniable that Wittgenstein does think that there is room for different colors, different ways of measuring and calculating, and different ways of inferring. In almost all of the cited passages, there is some line like this: "And yet we could imagine circumstances under which we would say, "These people see other colors in addition to ours." (Wittgenstein 1978 [RC]: III:42)

Here, Wittgenstein is not showing a mystical side. Rather, he observes that at the margins of our established linguistic practices, we frequently encounter novel circumstances, the handling of which requires alterations to our established grammar. This way, different kinds of color can become conceivable. Since color discourse is a well-established and well-functioning part of language, we should not expect practical insufficiencies there overly often. But every now and then, these things do happen.

It is quite possible that, under certain circumstances, we would say that people know colors that we don't know, but we are not forced to say this... This is like the case in which we speak of infra-red 'light'; there is a good reason for doing it, but we can also call it a misuse. And something similar is true with my concept 'having a pain in someone else's body'. (Wittgenstein 1978 [RC]: III:127)

Take the infra-red case. This scenario can be described just like our whale-example. We can 
easily imagine two opposing factions who argue as follows: "Light makes objects visible. Infra-red does not make objects visible. Therefore it is not light" versus "Light is the kind of radiation which helps us navigate and which is processed by the eyes. This is the case with infra-red (if we use nightsight devices). Therefore, this radiation comes under the concept of light." Here, then, we have two premises which are clearly taken to reflect the grammar of shared language, yet which, along with uncontroversial minor premises, come into conflict with one another in the face of the invention (or discovery) of infra-red radiation. Once one of them is given up, all previous judgments need to be carefully tested, since they were uttered in a previous stage in the development of language.

It might seem, in the light of the examples given, that linguistic evolution through grammatical revision is a rather rare phenomenon. This impression, however, is due solely to expository reasons. We must appreciate that our examples are drawn from areas of discourse whose inferential makeup is so well-established and simple that we rarely ever make remotely controversial judgments in them. In fact, we rarely ever make any explicit judgments in them. Conversely, when we formulate propositions in the real world, it is usually because they are not so obvious. It still remains the case, though, that they convey grammatical information. Once this is understood, linguistic evolution can be appreciated as an omnipresent phenomenon. Just take science, for instance, where we constantly revise the grammar around concepts like "quark", "genetic" or even "parallel". In fact, Robert Brandom, whose inferentialism does without the grammar-substantive distinction, comes to the conclusion that every novel proposition (in a given speech situation) changes the inferential machinery that is language, and thus the meanings of the concepts involved (see Brandom 2000, 2002).

Let me finally give an example from moral discourse. Ordinary people in ordinary circumstances operate with the background inferences from something being fun to it being worthy of support, and from something constituting torture to it being worthy of condemnation. Recently, it has been asked how we would deal with torturers who find their job "fun". ${ }^{18}$ This case is meant to shake our principled belief that if something is fun, it is always better or less bad than if it wasn't fun. Here, people disagree, but most of them respond to the "fun torture" case by saying that if an episode of torture is considered "fun" by the perpetrator, then this makes it even more abhorrent, not less so. These people are likely to conclude that their opponents' "moral principle" was wrong.

While I agree that torture (almost always) becomes even more abhorrent if its executioners enjoy it, I want to propose a different reading of what's going on. The "principle" in question was not meant to be of the kind that is true or false. It might have been controversial in the past, but these days are so long gone that today, no one even takes the trouble to state it explicitly ${ }^{19}$ - until a perplexing new case presents itself. When it is finally stated, moreover, it is stated as one of a pair of suddenly incompatible grammatical propositions. I want to suggest that we witness, here, an example of grammatical tension followed by a period of uncertainty as to how to resolve it. I interpret the majority opinion as a proposal for its solution. The proposal, in full, is to keep the inference from 
something constituting torture to it being wrong, and to reject the inference from something being fun to it being worthy of support, maybe to replace it with a more complex conditional.

This view has a few important consequences. Firstly, and most importantly for us, it does not imply any diagnosis of the kind of error which (in great doses) is harmful to cognitivism, even if many people continue to reject the majoritarian solution. Secondly, it implies that we must be very careful when confronting judgments that were uttered or written before the perplexing new case. It will, by now, be uncontroversial that terms like "fun" and/or "torture", and along with them many other terms, change their meaning during episodes of grammatical change. Thirdly, it implies that the common picture of "reasons pulling in different directions" is misleading, for some "reasons" turn out to be no reasons at all. Fourthly, it implies that there are or could have been alternative solutions to the grammatical tension which are not necessarily inferior to the one reported. For example, it could have been proposed to lean on yet another grammatical norm, namely "Only innocent activities can be fun", and thus to resist the diagnosis of "fun torture" in the first place. The phenomenon in question could have been interpreted as "torture with lust" instead. So conceived, it would not have intersected with the inference from being fun to being worthy of support. It is, however, important to note that anyone following this path may get involved in moral conflict with members of the majority.

\section{Conclusion: Warring Tautologies}

This way, we can show that once a Wittgensteinian diachronic theory of language is adopted, a third option besides factual disagreement and misunderstanding becomes available for moral dissent. With it, we can avoid the inflationary charge of observational error that is harmful to cognitivism. Thus, we can accommodate the prevalence of moral dissent while retaining the heart of any sensible cognitivism, namely the following three commitments: almost all moral utterances are propositions, most of them are meant to be true, and many of them in fact are.

Let me conclude this paper by sketching how we can react to three worries about the theory. The worries I have in mind can be expressed by modus tollens arguments, each one attempting to show that the theory has a problematic implication. Since my reaction to each of them is to openly embrace the supposedly problematic implication, let me just list the arguments' respective major premises.

Firstly, it follows from the theory that natural language divides into a very large number of separate calculi. This is the case both over time, since every time a minor grammatical proposition is rejected, a new calculus comes into existence; and across speakers, because the revisions do not happen in one global discussion, but in a myriad of concrete conversations. Secondly, it follows from the theory that we are frequently forced to make grammatical decisions which may even 
become binding for future speakers. Thirdly, it follows from the theory that there is no room for moral principles, neither all-out, nor even pro-tanto.

It must, all in all, be admitted that the theory demands quite a bit from us. However, we can afford the implications; in fact, we should welcome them as important pieces of theoretical insight. The third consequence has perhaps the greatest relevance in current philosophy, for it directly bears upon the hot issue of "particularism".

Let us start with the first consequence, though. It demands a revision of our theoretical concept of "language". In itself, this need not, of course, scare us. But since according to the revised notion, language consists of many separate calculi which, moreover, chaotically overlap and evolve, so that it happens rarely or never that two speakers inhabit exactly the same calculus, it needs to be shown how communication is at all possible. As Donald Davidson has shown in his essay " $A$ Nice Derangement of Epitaphs" (1986), however, this is only the semblance of a problem. To see this, it should suffice (for our purposes) to call a few simple facts to mind. Firstly, in a grammatical revision, only a fraction of a concept's many logical connections is rejected. Secondly, most novel phenomena which lead to grammatical tension can be detected across contexts and language games. Thirdly, speakers usually do more than utter isolated propositions: they convey a host of grammatical information and can thus inform each other about grammatical revisions effected in the past. Fourthly, speakers are usually capable of inhabiting multiple calculi at the same time, keeping different grammatical rules apart. Fifthly and most importantly, there is no reason to expect that speakers always and everywhere understand each other perfectly - especially not in ethics. ${ }^{20}$

The second implication, namely the burden of frequent and weighty grammatical decisions, could meet with some resistance if it is thought that it must always be possible, in a game, to remain passive with respect to the game's rules. In chess or football, after all, we are never forced to take a stance on what rules we - and future players - are to play by. In natural language, however, we are frequently confronted with incompatible rules, and incompatible rules cannot be accepted (it is not even clear what it would mean to accept them). Of course, we can always say: "At this point, I no longer know how to go on." But this would be a decision to end the game. Every other decision necessarily involves taking a stance against some rule or another. These decisions, of course, can be taken with more or with less consideration. Speakers who habitually decide without care are responsible for inefficient and strange practices with complex and winding rules - unless they are overruled. Wittgensteinians know this phenomenon, by the way, under the name of "family resemblances" (Wittgenstein 2001 [PI]: I:66f.). Wittgenstein's example of this was the impossibility of defining the concept "is a game" in a non-disjunctive way: the set of games is "a complicated network of similarities overlapping and criss-crossing" (Wittgenstein 2001 [PI]: I:66), just like "the various resemblances between members of a family - build, features, color of eyes, gait, temperament, etc. etc." (Wittgenstein 2001 [PI]: I:67). Family resemblances, then, show how linguistic communities can be stuck with the bad grammatical decisions of their ancestors. ${ }^{21}$ 
The third implication, finally, is that there is no room for moral principles. As I said, this is the most interesting implication. As it stands, though, it is unclearly formulated, for there certainly are a kind of principles at play: we have, after all, grammatical rules to draw on. Remember that in a Wittgensteinian setting, such rules are not just about language, but about language games. Still, these are not the kind of principles the critic asks for. There is one aspect of grammatical rules that he is unhappy with: when they come into the kind of conflict envisioned in our examples, there is no straightforward way to predict which will persist and which will perish. For that, we have no principle.

The best way to respond to this criticism is to argue that no such principle is needed for the kinds of things we do when we engage in moral deliberation. It is true that the kind of principle demanded by the critic is only available inside a calculus: once we talk about how to extend a given calculus beyond its familiar domain, there is nothing to provide the same sort of certainty. However, we $d o$ have recourse to arguments, even beyond the certainty of the calculus. In our arguments, we employ grammatical rules as premises. Moreover, since grammatical rules are always connected with other grammatical rules, we can use those in further arguments for our premises. If, for example, we need to support the premise that if something is torture, then it is worthy of condemnation, we can argue that torture amounts to reducing the victim to a (suffering) body, and that that is worthy of condemnation. Of course, it may well be that other people argue against us, also relying on pieces of grammar. But this should not worry us any more than it does in other cases where we face rational opposition. The best solution will reflect, in the least revisionary and the most economic way, what we care about, just like in the whale-example. Note that we also have no need for "pro tanto" principles, which are associated with the picture of reasons pulling in different directions with different strengths. A theory with just one "pull", which is determined by which of the conflicting bits of grammar are kept and which rejected, will do the job just as well.

Is our theory, then, "particularistic"? The answer is no. We are following a third path beside generalism and particularism, for the goal in every grammatical revision is the construction of a consistent new language game in which all of the old moral problems are erased and every new case can be handled by uncontroversial rules. We might expect, of course, that new problems will emerge in the future. But then, another grammatical revision will be called for. The danger of grammatical collisions will only be removed when we have run out of things to say.

In conclusion, then, if there are problems in moral cognitivism, the prevalence of moral dissent is not one of them. 


\section{Notes}

${ }^{1}$ In Wittgenstein quotes, I have included the following abbreviations for convenience: PI: Philosophical Investigations, TLP: Tractatus Logico-Philosophicus, OC: On Certainty, RFM: Remarks on the Foundations of Mathematics, RC: Remarks on Color, LE: A Lecture on Ethics. The numbers refer to the part and the section, not the page.

${ }^{2}$ See Wittgenstein 1965 [LE]: 3-12 and the closing remarks of Wittgenstein 2002 [TLP].

${ }^{3}$ See Sellars 1997 : esp. sec. 3 and 8. For a good exposition of the Sellarsian account (and for a few sensible alterations which I am inclined to incorporate without much ado) also see Brandom 1994. Note, however, that Lovibond herself does not acknowledge the Sellarsian connection in her book. In fact, she favors a truth-conditional semantics, which is also more in line with Mark Platts' work. My cognitivist conception of moral discourse is thus rather freely inspired by Lovibond.

${ }^{4}$ A relatively early exposition of this view can be found in Sellars $2007 \mathrm{~b}$.

${ }^{5}$ For a complete exposition of this view, see Hurley 1989 : esp. ch. 2, 3 and 10. Explicit affirmation comes from Pettit and Jackson 2004. For the opposing view, the locus classicus is Hare 1981, esp. chapter 4.

${ }^{6}$ In Sellarsian jargon, this would be "language-exit transitions".

${ }^{7}$ Lovibond is also clearly committed to this assumption: "The only way," she writes, "in which an indicative statement can fail to describe reality is by not being true - i.e. by virtue of reality not being as the statement declares it to be..." (Lovibond $1983: 26$ )

${ }^{8} \mathrm{I}$ am, however, following the idea much further than Diamond's essay warrants.

${ }^{9}$ A good introduction into this view is, again, Brandom 1994. See also the various texts collected in Sellars 2007a and, with a view to the history of the view, Frege 1997.

${ }^{10}$ Something like this is what Wittgenstein had in mind when he wrote: "In life it is never a mathematical proposition which we need, but we use mathematical propositions only in order to infer from propositions which do not belong to mathematics to others which equally do not belong to mathematics." (Wittgenstein 2002 [TLP]: 6.211, excerpt)

${ }^{11}$ See also Wittgenstein 1978 [RC]: III:19 and Wittgenstein 1972 [OC]; 309

${ }^{12}$ Note that I do not say that the problem lies in the cases in which we have to diagnose disagreement, yet in which we just cannot say who is wrong, and exactly how so. Since this is also a frequent phenomenon in scientific discussions, it does not speak against cognitivism. Note also that the problem is not just that we have to diagnose error, but that we have to diagnose unexplained error. By this, I do not mean to deny, of course, that there may also be explainable error in ethics. On the contrary, there are many erroneous judgments in ethics that can be attributed to the distortive effects of religion and tradition, just like in scientific discourse. I am inclined, however, to take seriously the thought that in ethics, there is a surplus of dissent which is not caused by such distortion, and which pushes the cognitivist to diagnose a lot of error for purely theoretical reasons. Our problem, then, is a classic interpretive problem: if we diagnose too much unexplained observational error, we run against the principle of charity.

${ }^{13}$ Note, by the way, that it can be quite harmful to treat a grammatical proposition as capable of being false (hence as informative, as empirical). This, at any rate, is Wittgenstein's famous warning in the context of remarks like "My left hand cannot make a gift to my right hand", "something green cannot be reddish, though it can be blueish", and also of remarks like "The earth has existed for more than five minutes". If taken as empirical statements, they are likely to lead us to wonder how we can be so sure of these things, and to write whole books about our endeavors to find out. In the context of this danger, it might be said that there is a fourth use of grammatical propositions, namely the therapeutical use. I am not strongly opposed to this view; I just haven't included this use in my list because it seems to me that the actual "therapy" consists in the reminder that these propositions are used grammatically. If it is felt that the way to bring this out is by formulating grammatical propositions, I am happy to include it. At any rate, the therapeutical side of Wittgenstein is not the subject of this paper.

${ }^{14}$ Another reason for being interested in a diachronic theory is that it may enable us to dispel the idea that syntax can veil the "logical form" of thoughts (as was Frege's idea in his Begriffsschrift). Hans Julius Schneider has explored this theme in Schneider 1992. Consider, as an example, the thesis that an utterance like "Peter has a toothache" is indicative of the logical structure of pain, while this same structure is veiled, or hidden from view, in an utterance like "Peter's tooth hurts" ("the tooth doesn't do anything!"). Schneider argues that such theses are confusions stemming from a lack of understanding of linguistic evolution. What happens is just that when a new kind of language game arises out of the need for a new kind of communal coordination, it draws on and thus extends existing syntactical patterns. Schneider calls such extensions "syntactical metaphors". Often, several such extensions, sometimes dating from different historical epochs, constitute discursive alternatives. In our example, it is quite plausible that the syntactical pattern "to have an $x$ " was extended, in the past, from discourse about physical objects to discourse about pain, and that (perhaps a little later, but this is of no great concern) the syntactical pattern "x hurts" was extended from people to limbs and wounds. 
Eventually, we thus ended up with two alternative ways of expressing that we are in (a particular kind of) pain. Once we see the genesis of each, we are no longer compelled to say that one is more basic than the other. Incidentally, this kind of view also helps us guard against the idea that there is some sort of philosophical problem in finding a place for mental phenomena in the physical world (see also Schneider 2005).

${ }^{15}$ Actual zoology is more messy, but for our purposes, this sketch will do.

${ }^{16}$ By meta-reason, I mean a consideration of theoretical virtue (such as theoretical economy or elegance). In the moral example (below), it will come out quite clearly that they are usually not given within a discussion ensuing a grammatical tension, although ordinarily, speakers will aim for solutions reflecting them.

${ }^{17}$ See Wittgenstein 2001 [PI]: I: 2, 6-8, 18-21 among others.

${ }^{18}$ This is one of the standard examples of particularists and can be found in many books and articles on Moral Particularism. It is mentioned, for example, in Jackson at al. 2003.

${ }^{19}$ Again, see Wittgenstein 1972 [OC]: 210f.: "Much seems to be fixed, and it is removed from the traffic. It is so to speak shunted onto an unused siding. Now it gives our way of looking at things, and our researches, their form. Perhaps it was once disputed. But perhaps, for unthinkable ages, it has belonged to the scaffolding of our thoughts. (Every human being has parents)"

${ }^{20}$ All this should convince us "that there is no such thing as a language, not if a language is anything like what many philosophers and linguists have supposed.” (Davidson 1986 : 446)

${ }^{21}$ It might be interesting to inquire further into this "path-dependence" of language games. 


\section{References}

BRANDOM, R. B. (1994). Making It Explicit. Reasoning, Representing, and Discursive Commitment. Cambridge Mass.: Harvard University Press.

. (2000). Vocabularies of pragmatism: Synthesizing naturalism and historicism.

In.: R. B. Brandom (Ed.), Rorty and his Critics, pp. 165-182. Oxford: Blackwell.

. (2002). Some pragmatist themes in Hegel's idealism. In.: Tales of the Mighty Dead, pp. 210-234. Cambridge Mass.: Harvard University Press.

DAVIDSON, D. (1986). A nice derangement of epitaphs. In.: E. LePore (Ed.), Truth and Interpretation. Perspectives on the Philosophy od Donald Davidson, pp. 433-446. Oxford: Blackwell.

DIAMOND, C. (1996). Wittgenstein, mathematics, and ethics: Resisting the attractions of realism. In.: H. D. Sluga and D. G. Stern (Eds.), The Cambridge Companion to Wittgenstein, pp. 226-260. Cambridge, New York: Cambridge University Press.

FREGE, G. (1997). The Frege Reader. Oxford: Blackwell.

HARE, R. M. (1981). Moral Thinking. Its Levels, Methods, and Point. Oxford: Clarendon.

HURLEY, S. L. (1989). Natural Reasons. Personality and Polity. New York: Oxford University Press.

JACKSON, F., P. Pettit, and M. Smith (2003). Ethical particularism and patterns. In.: B. Hooker and M. O. Little (Eds.), Moral Particularism, pp. 79-99. Oxford: Clarendon Press and Oxford University Press.

LOVIBOND, S. (1983). Realism and Imagination in Ethics. Oxford: Blackwell.

PETTIT, P. and JACKSON, F. (2004). Moral functionalism and moral motivation. In.: Jackson, F.; PETTIT, P. and SMITH, M. (Eds.), Mind, Morality and Explanation, pp. 189-210. Oxford: Clarendon Press and Oxford University Press.

PLATTS, M. D. (1979). Ways of Meaning. An Introduction to a Philosophy of Language. London: Routledge \& Kegan Paul.

SCHNEIDER, H. J. (1992). Phantasie und Kalkül. Frankfurt am Main: Suhrkamp.

. (2005). Reden über Inneres. Wittgensteins Auflösung des Leib-Seele-Problems.

In.: T. Rentsch (Ed.), Einheit der Vernunft? , pp. 126-148. Paderborn: mentis.

SELLARS, W. (1997). Empiricism and the Philosophy of Mind. Cambridge Mass.: Harvard University Press. . (2007a). In the Space of Reasons. Cambridge Mass.: Harvard University Press. 
. (2007b). Inference and meaning. See (Sellars 2007a), pp. 3-27.

. (2007c). Some reflections on language games. See (Sellars 2007a), pp. 28-56.

WIGGINS, D. (1998). Truth, invention, and the meaning of life. In.: Needs, Values, Truth: Essays in the Philosophy of Value, pp. 87-139. Oxford: Clarendon.

WILLIAMS, B. (1984). Ethics and the Limits of Philosophy. Cambridge Mass.: Harvard University Press.

WITTGEnStEIn, L. (1965, January). A lecture on ethics. The Philosophical Review 74(1), $3-12$.

. (1972). On Certainty. Über Gewissheit. New York, Hagerstown, San Francisco, London: Harper \& Row.

. (1978). Remarks on Colour. Bemerkungen über die Farben. Oxford:

Blackwell.

. (1983). Remarks on the Foundations of Mathematics. Cambridge Mass.:

MIT Press.

. (2001). Philosophical Investigations. Philosophische Untersuchungen.

Oxford: Blackwell. . (2002). Tractatus Logico-Philosophicus. London: Routledge 